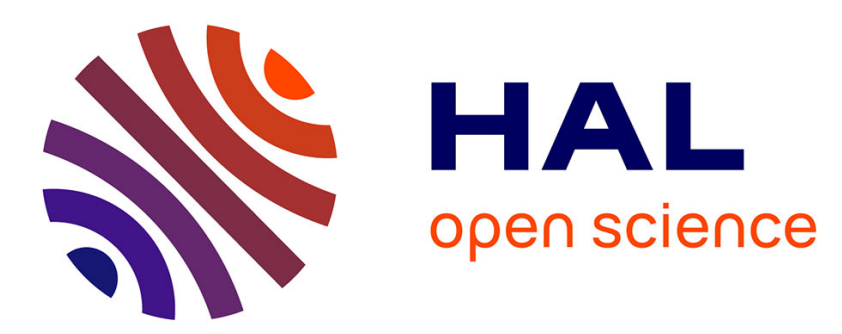

\title{
Oxidation induced changes in viscoelastic properties of a thermostable epoxy matrix
}

\author{
Svetlana Terekhina, Marion Mille, Bruno Fayolle, Xavier Colin
}

\section{To cite this version:}

Svetlana Terekhina, Marion Mille, Bruno Fayolle, Xavier Colin. Oxidation induced changes in viscoelastic properties of a thermostable epoxy matrix. Polymer Science Series A / Vysokomolekulyarnye Soedineniya, Ser. A., 2013, 55, pp.614-624. 10.1134/S0965545X13090058 . hal-01001693

\section{HAL Id: hal-01001693 https://hal.science/hal-01001693}

Submitted on 4 Jun 2014

HAL is a multi-disciplinary open access archive for the deposit and dissemination of scientific research documents, whether they are published or not. The documents may come from teaching and research institutions in France or abroad, or from public or private research centers.
L'archive ouverte pluridisciplinaire HAL, est destinée au dépôt et à la diffusion de documents scientifiques de niveau recherche, publiés ou non, émanant des établissements d'enseignement et de recherche français ou étrangers, des laboratoires publics ou privés. 


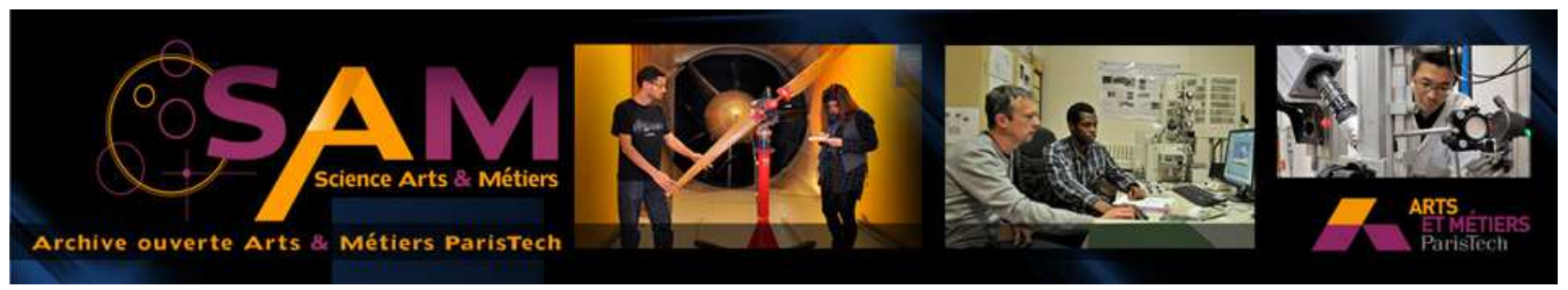

Science Arts \& Métiers (SAM)

is an open access repository that collects the work of Arts et Métiers ParisTech researchers and makes it freely available over the web where possible.

This is an author-deposited version published in: http://sam.ensam.eu

Handle ID: .http://hdl.handle.net/10985/8226

\section{To cite this version :}

Svetlana TEREKHINA, Marion MILLE, Bruno FAYOLLE, Xavier COLIN - Oxidation induced changes in viscoelastic properties of a thermostable epoxy matrix - Polymer Science - Series A Vol. 55, p.614-624 - 2013 


\title{
Oxidation induced changes in viscoelastic properties of a thermostable epoxy matrix
}

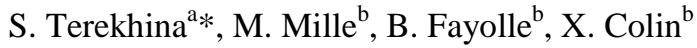 \\ ${ }^{a}$ ARTS ET METIERS ParisTech, LAMPA, 2 boulevard du Ronceray, BP 93525, 49035 Angers, France \\ ${ }^{b}$ ARTS ET METIERS ParisTech, PIMM UMR 8006, 151 boulevard de l'Hôpital, 75013 Paris, France \\ *Svetlana.TEREKHINA@ensam.eu
}

\begin{abstract}
The thermal ageing of a neat epoxy matrix has been studied at $200^{\circ} \mathrm{C}$ in air by three complementary analytical techniques: optical microscopy, mechanical spectrometry and nanoindentation. Thermal oxidation is restricted in a superficial layer of about $195 \mu \mathrm{m}$ of maximal thickness. It consists in a predominant chain scission process involving, in particular, chemical groups whose $\beta$ motions have the highest degree of cooperativity and thus, are responsible for the high temperature side of $\beta$ dissipation band. As a result, chain scissions decrease catastrophically the glass transition temperature, but also increase significantly the storage modulus at glassy plateau between $\mathrm{T}_{\beta}$ and $\mathrm{T}_{\alpha}$. This phenomenon is called "internal antiplasticization".

Starting from these observations, the Di Marzio and Gilbert's theories have been used in order to establish relationships between the glass transition temperature and number of chain scissions, and between the storage modulus and $\beta$ transition activity respectively. The challenge is now to establish a relationship between the $\beta$ transition activity and the concentration of the corresponding chemical groups.
\end{abstract}

Keywords: neat epoxy matrix, thermal ageing, chain scissions, glass transition temperature, Young's modulus, internal antiplasticization. 


\section{Introduction}

There is a lack of organic matrix composite materials for civil aeronautical applications above $200^{\circ} \mathrm{C}$ in Europe. Highly aromatic epoxy matrices are candidate for such applications because of their high thermomechanical performances. These thermostable matrices have the ability to maintain their elastic and fracture properties up to temperatures close to their glass transition temperature (typically $\left[\mathrm{T}_{\mathrm{g}}-30^{\circ} \mathrm{C}\right]$ ). However, they will be used by airline companies only if their long-term durability in current use conditions is clearly demonstrated.

There is large amount of literature works devoted to the thermal degradation mechanisms and kinetics of epoxy matrices showing that oxidation is clearly the predominant ageing process [1-4]. A key feature of such process is that degradation is non-uniform in the sample thickness because oxidation kinetics is diffusion controlled. A non-empirical kinetic model has been derived from a realistic oxidation mechanistic scheme for epoxy matrices in order to access the spatial distribution (in the sample thickness) of structural changes at the molecular scale as a function of exposure time [1-4]. This mechanistic scheme can be summarized as follows:
(1) Initiation:
$\delta \mathrm{POOH} \rightarrow \alpha \mathrm{P}^{\circ}+\mathrm{PPO}_{2}^{\circ}+\mathrm{H}_{2} \mathrm{O}$
(2) Propagation:
$\mathrm{P}^{\circ}+\mathrm{O}_{2} \rightarrow \mathrm{PO}_{2}^{\circ}$
(3) Propagation
$\mathrm{PO}_{2}^{\circ}+\mathrm{PH} \rightarrow \mathrm{POOH}+\mathrm{P}^{\circ}$
(4) Termination:
$\mathrm{P}^{\circ}+\mathrm{P}^{\circ} \rightarrow$ inactive products
(5) Termination:
$\mathrm{P}^{\circ}+\mathrm{PO}_{2}^{\circ} \rightarrow$ inactive products
(6) Termination: $\mathrm{PO}_{2}^{\circ}+\mathrm{PO}_{2}{ }_{2} \rightarrow$ inactive products $+\mathrm{O}_{2}$

where $\mathrm{POOH}, \mathrm{P}^{\circ}, \mathrm{PO}^{\circ}{ }_{2}, \mathrm{PH}$ and $\mathrm{O}_{2}$ represent hydroperoxides, alkyl and peroxy radicals, polymer substrate and oxygen respectively.

$\delta$ is the molecularity of initiation reaction such as:

- if $\delta=1$, then $\alpha=2$ and $\beta=0$

- else if $\delta=2$, then $\alpha=\beta=1$

and $\mathrm{k}_{\mathrm{i}}$ are elementary rate constants.

It is a radical chain oxidation producing its own initiator: hydroperoxide $\mathrm{POOH}$. This closedloop character is responsible for the sharp auto-acceleration of thermal oxidation at the end of the induction period [5].

There is also an important amount of literature works devoted to the consequences of oxidation on viscoelastic and/or mechanical properties of epoxy matrices [6-8]. Most of the authors try to relate directly the oxidation conversion ratio to these macroscopic properties, whereas it is now well established that these latter are essentially altered by structural changes taking place not at the molecular, but rather at the macromolecular scale as chain scission or crosslinking process [9].

The objective of the present article is to complete the previous non-empirical kinetic model in order to predict, in a near future, the consequences of oxidation on viscoelastic properties of epoxy matrices. This operation will involve two consecutive stages: 
- Firstly, main reactions responsible for the structural changes taking place at the macromolecular scale, i.e. chain scissions and crosslinking, will be briefly recalled and introduced in the mechanistic scheme. As a result, two new kinetic equations, giving access to the numbers of chain scissions $(\mathrm{S})$ and crosslinking events $(\mathrm{X})$ versus exposure time, will be derived from the mechanistic scheme.

- Secondly, the Di Marzio [10] and Gilbert's theories [11] will be used to establish nonempirical relationships between $S$ and $X$ and particularly important viscoelastic properties for aeronautical applications: glass transition temperature $\left(\mathrm{T}_{\mathrm{g}}\right)$ and Young's modulus (E) respectively. Since the coefficients of these equations have a real physical meaning, their values will be assessed from the theoretical structure of the virgin epoxy network under study.

\section{Experimental}

\subsection{Material}

The ideal epoxy network under study results from the reaction of a mixture of two epoxide monomers: tris(4-hydroxyphenyl)methane triglycidyl ether (Tactix 742) and diglycidyl ether of bisphenol A (Tactix 123), with an aromatic diamine hardener: 4,4-diaminodiphenyl sulfone (DDS). The chemical structures of these products and their mass fraction are given in Fig. 1 and Tab. 1 respectively.<smiles>c1cc(C(c2ccc(OCC3CO3)cc2)c2ccc(OCC3CO3)cc2)ccc1OCC1CO1</smiles>

a)

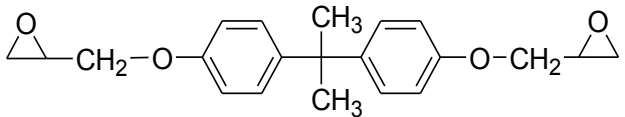

b)<smiles>Nc1ccc(S(=O)(=O)c2ccc(N)cc2)cc1</smiles>

c)

Figure 1: Chemical structures of monomers: a) Tactix $742\left(\mathrm{M}=460.5 \mathrm{~g}^{\mathrm{mol}}{ }^{-1}\right)$; b $)$ Tactix $123(\mathrm{M}=$ 340.4 g.mol $\left.{ }^{-1}\right)$; c) DDS $\left(M=248.3\right.$ g.mol $\left.{ }^{-1}\right)$. 
Table 1: Mass fraction of monomers for synthetizing the ideal epoxy network.

\begin{tabular}{|c|c|}
\cline { 2 - 2 } \multicolumn{1}{c|}{} & Mass fraction (\%) \\
\hline Tactix 742 & 54.3 \\
\hline Tactix 123 & 18.1 \\
\hline DDS & 27.6 \\
\hline
\end{tabular}

Neat epoxy plates (of $2 \mathrm{~mm}$ thick) were processed by autoclave moulding in accordance with the recommended cure cycle: 1 hour at $140^{\circ} \mathrm{C}$ and $3 \mathrm{~h}$ at $180^{\circ} \mathrm{C}\left(\right.$ ramp: $\left.2^{\circ} \mathrm{C} \cdot \mathrm{min}^{-1}\right)$. Then, the samples were post-cured at $230^{\circ} \mathrm{C}$ for 10 hours under primary vacuum in order to reach the maximum crosslinking density while preventing any pre-oxidation before thermal ageing.

\subsection{Test conditions and characterization}

\subsubsection{Ageing conditions}

All the plates were stored in the dry atmosphere of a desiccator prior thermal ageing experiments. They were subjected to isothermal exposure at $200^{\circ} \mathrm{C}$ in an air-circulating oven and were removed intermittently to be characterized by optical microscopy, mechanical spectrometry and nano-indentation.

\subsubsection{Optical microscopy examinations}

Optical microscopy examinations were performed using an interferential contrast in order to better visualize the superficial oxidized layer and, then, try to determine its average thickness. Sample cross-sections were polished with a series of abrasive papers classified according to a decreasing order of the particle size of silicon carbide (from 600 to 4000). Then, a mirror finish was obtained with a diamond paste (of particle diameter ranged between 1 and $3 \mu \mathrm{m}$ ). Finally, all surfaces to be examined were ultrasonically cleaned in ethanol for 5 $\min$.

\subsubsection{Mechanical spectrometry analysis}

Mechanical spectrometry is a convenient and sensitive technique for a rapid determination of the viscoelastic properties of polymers and polymer-based materials as a function of frequency and temperature. It consists in the observation of the time-dependent behaviour of a material under a dynamic periodic sinusoidal strain or stress.

In this study, the analysis was performed on parallelepipedic barrels $\left(25 \times 2 \times 1 \mathrm{~mm}^{3}\right)$ machined from plate in a tension/compression mode with a Dynamic Mechanical Analyzer (DMA Q800, TA Instruments). The tests were carried out at a controlled strain in the linear domain of material viscoelasticity and the corresponding stress was measured. From stress and strain values, the complex modulus was calculated:

$E^{*}=E^{\prime}+j E^{\prime \prime}$ 
where $\mathrm{E}^{\prime}$ is the storage (elastic component) modulus, E" is the loss (viscous component) modulus and $\tan \delta=\mathrm{E}^{\prime \prime} / \mathrm{E}^{\prime}$ is the loss factor or damping, from which the phase shift $\delta$, between stress and strain, is extrapolated.

The frequency was set at $1 \mathrm{~Hz}$. The temperature was ranged from $-110^{\circ} \mathrm{C}$ to $330^{\circ} \mathrm{C}$ at a heating rate of $2^{\circ} \mathrm{C} \cdot \mathrm{min}^{-1}$. The glass transition temperature, associated to the principal relaxation $\left(\mathrm{T}_{\alpha}\right)$, was taken at the maximum of the $\alpha$ dissipation band.

\subsubsection{Nano-indentation measurements}

Indentation measurements were performed with the nano-indenter of an atomic force microscope (AFM, Veeco) [12]. The force-displacement curve $(F=f(\delta))$ collected during the indentation experiment provides indications on both material mechanical and physical properties. The "indentation elastic modulus" ( $\left.\mathrm{E}^{\mathrm{i}}\right)$ was calculated from the slope of the curve at $\mathrm{F}=\mathrm{F}_{\max }$ by Eq. 2 :

$$
E^{i}=\frac{\sqrt{\pi} \cdot \frac{d F}{d h}}{2 \gamma \sqrt{A_{P}}}
$$

where $\gamma$ is a parameter depending on the indenter type $(\gamma=1.013$ for a Vickers indenter) and $A_{p}$ is the contact area between the indenter and the sample, projected on the plane perpendicular to the indenter axis: $A_{p}=1 / 2(h \times b), h$ and $b$ being the height and the base of the projected equilateral triangle.

\section{Results}

\subsection{Determination of the thickness of oxidized layer}

A superficial oxidized layer was clearly evidenced by optical microscopy according to the procedure described in the experimental section. This latter appears rougher and brighter than the specimen core. Example of micrograph for sample aged 3402 hours at $200^{\circ} \mathrm{C}$ in air is given in Fig. 2. By choosing the whole depth of visible changes as arbitrary criterion for defining the skin/core boundary, a thickness of oxidized layer (TOL) was determined. In Fig. 2 , it can be seen that TOL increases with exposure time to finally tend towards an asymptotic value of about $195 \mu \mathrm{m}$ after 1000 hours of exposure. 


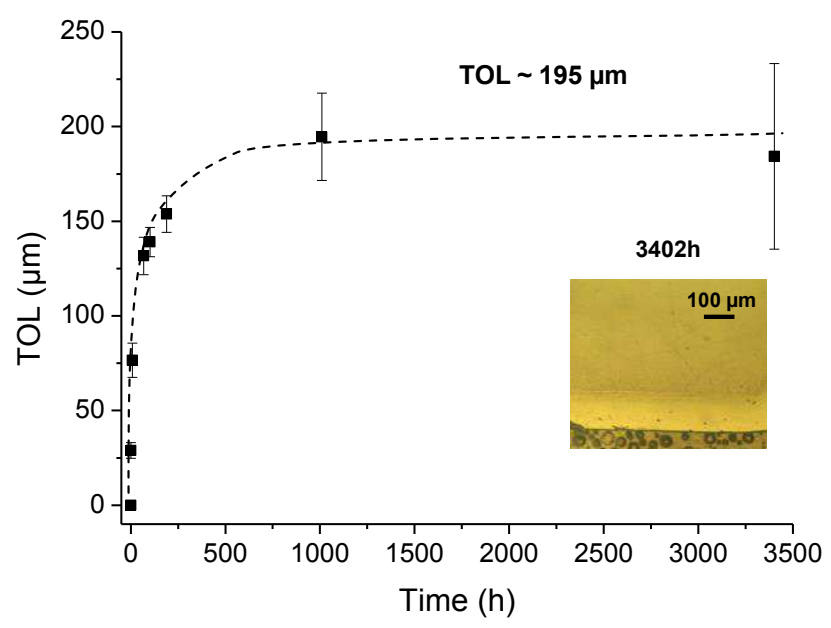

Figure 2: Average thickness of oxidized layer (TOL) versus exposure time at $200^{\circ} \mathrm{C}$ in air. Micrograph of sample aged during $3402 \mathrm{~h}$ is included.

\subsection{Effect of oxidation on the viscoelastic properties of epoxy network}

The storage modulus and the loss factor $\operatorname{Tan} \delta$ ( $\operatorname{Tan} \delta=$ E' / E') of a virgin sample and a sample aged $3402 \mathrm{~h}$ at $200^{\circ} \mathrm{C}$ in air are represented as a function of temperature in Figure 3. From -110 to $300^{\circ} \mathrm{C}$, three distinct physical transitions are clearly highlighted:

i) $\beta$ and $\omega$ subglass transitions are located around $-70^{\circ} \mathrm{C}$ and $+75^{\circ} \mathrm{C}$ respectively. $\beta$ transition is initiated by molecular motions of small amplitude of a limited number of atoms. In epoxy networks, they are rotations (of crankshaft type) of $\mathrm{C}-\mathrm{C}$ bonds localized in the hydroxypropylether unit [13-14]. In contrast, the origin of $\omega$ transition is still a subject of discussion in the literature [15-18]. It is often associated with the presence of water [15] or unreacted epoxy groups [16-17]. It is also sometimes assigned to rotations of p-phenylene rings [18].

ii) $\alpha$ principal transition is initially located around $263^{\circ} \mathrm{C}$. It is associated to glass transition temperature $\left(\mathrm{T}_{\mathrm{g}}\right)$. It is initiated by molecular motions of large amplitude of long chain segments (involving typically between 50 and 100 carbon atoms). 

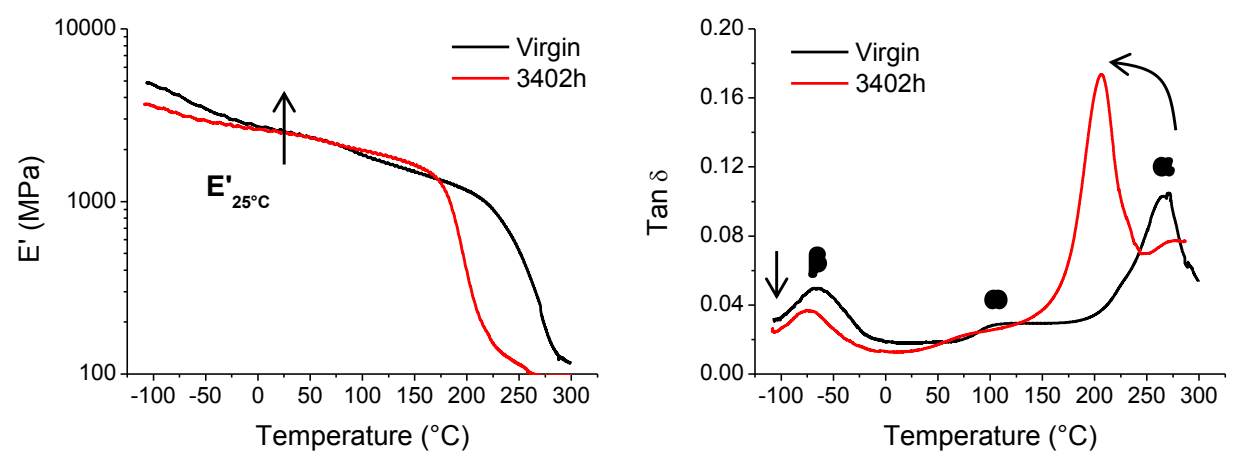

Figure 3: Thermomechanical spectra before and after 3402 hours at $200{ }^{\circ} \mathrm{C}$ in air. Left: Storage modulus; Right: Loss factor.

According to Figure 3, oxidation affects significantly $\alpha$ transition. Indeed, $\mathrm{T}_{\alpha}$ decreases significantly after $3402 \mathrm{~h}$ at $200^{\circ} \mathrm{C}$ in air (from $263^{\circ} \mathrm{C}$ to $203^{\circ} \mathrm{C}$ ), indicating a predominant chain scission process [9]. In addition, the height of $\alpha$ dissipation band increases, while its width at half-height decreases. Such changes result certainly from an increase in molecular mobility. It can be thus concluded that oxidation induces a predominant chain scission process.

Oxidation affects also $\beta$ transition, but at a lower extent. It leads to a disappearance of the high temperature side of $\beta$ dissipation band, thus causing an increase in the storage modulus (E') at glassy plateau between $T_{\beta}$ and $T_{\alpha}$. It can be thus assumed that oxidation takes place on $\mathrm{C}-\mathrm{H}$ bonds located in $\alpha$ position of oxygen atoms in the hydroxypropylether unit. Different oxidation pathways leading to chain scissions can be envisaged, but the most probable scenario is schematized in Fig. 4.

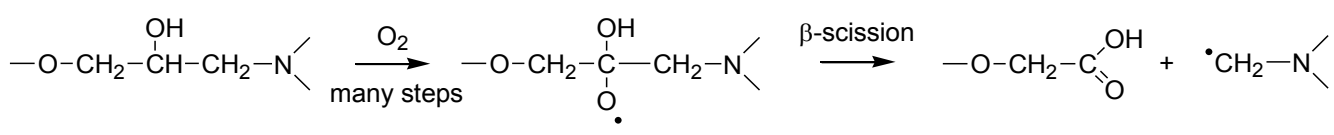

Figure 4: Most probable scenario for chain scission in epoxy network.

If one considers, in a first approximation, that the diffusion control of oxidation kinetics transforms a (virgin) homogeneous epoxy plate into a skin/core structure, the global storage modulus can be expressed from a simple mixture law at $298 \mathrm{~K}\left(25^{\circ} \mathrm{C}\right)$ :

$E^{\prime}\{298 K\}=v_{o x} E^{\prime}\{o x, 298 K\}++\left(1-v_{o x}\right) E^{\prime}\{$ core, $298 K\}$

where $\mathrm{E}^{\prime}\{$ ox, 298K $\}$ and $\mathrm{E}^{\prime}\{$ core, $298 \mathrm{~K}\}$ are the average values at $25^{\circ} \mathrm{C}$ of the storage modulus in oxidized layer and intact core respectively, and $\mathrm{v}_{\mathrm{ox}}$ is the volumic fraction of detectable oxidized regions in the epoxy plates. Assuming that the sample geometry can be considered as a semi-infinite geometry where only two surfaces have been oxidized, $v_{0 x}$ can be written as: 
$v_{O X}=\frac{2 T O L}{L}$

with $\mathrm{L}$ the sample thickness $(\mathrm{L}=2 \mathrm{~mm})$.

The values at $25^{\circ} \mathrm{C}$ of E' (determined by DMA) and E' $\{$ ox, 298K\} (deduced from Eq. 3) have been plotted versus exposure time in Fig. 5. It can be concluded that oxidation leads to a dramatic increase in the elastic modulus (about $50 \%$ of its initial value) in the superficial layers of epoxy plates.

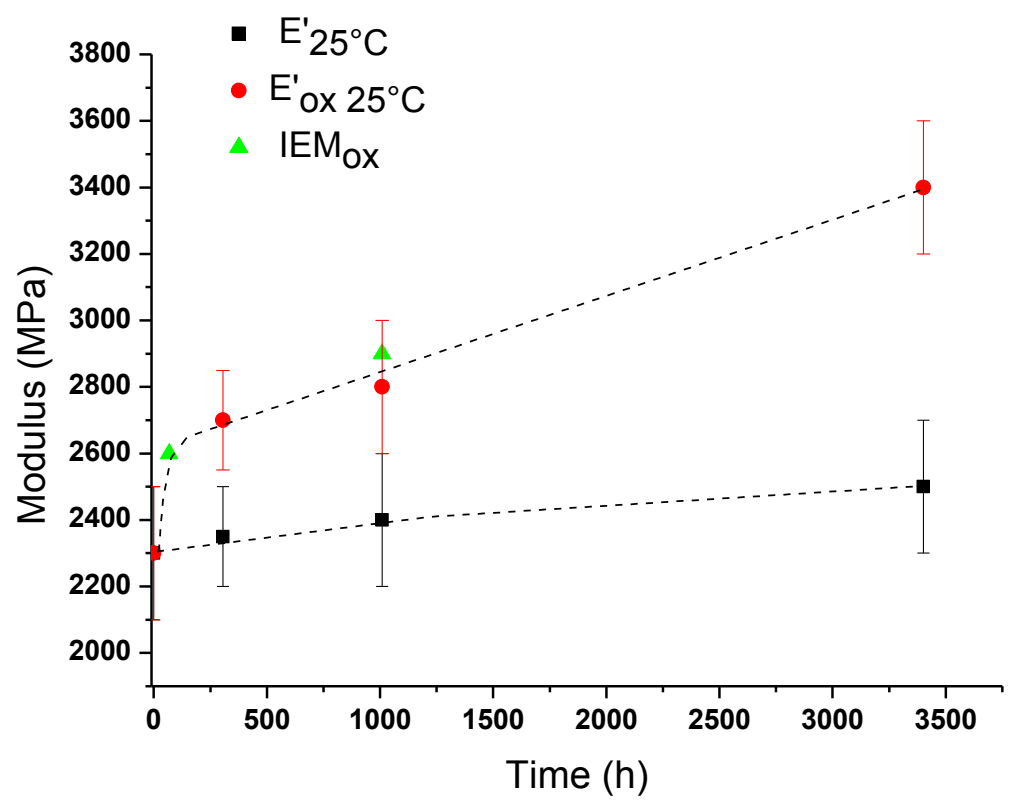

Figure 5: Global storage modulus $E^{\prime}\{298 \mathrm{~K}\}$ versus exposure time at $200^{\circ} \mathrm{C}$ in air. Comparison with average values of storage modulus $E^{\prime}\{0 x, 298 K\}$ and average indentation elastic modulus $E^{i}$ \{ox, 298K\} of oxidized layer.

These trends were checked by analyzing the superficial layers of epoxy plates with the nano-indenter of an AFM. Examples of $\mathrm{E}^{\mathrm{i}}$ profiles (in the sample thickness) after $0 \mathrm{~h}, 68 \mathrm{~h}$ and 1010 hours at $200^{\circ} \mathrm{C}$ in air are reported in Fig. 6. These results can be summarized as follows:

- TOL is about $180 \mu \mathrm{m}$ after 1010 hours, i.e. very close to the value previously determined by optical microscopy.

- $E^{1}$ increases significantly (of about $63 \%$ after 1010 hours) at the sample surface. Average $\mathrm{E}^{\mathrm{i}}$ modulus values for oxidized layer are calculated from the following relationship: $E^{i}\left\{o x, 25^{\circ} \mathrm{C}\right\}=\frac{1}{T O L} \int_{z=0}^{z=180 \mu m} E^{i}\left\{o x, 25^{\circ} C\right\}(z) \cdot d z$

Average values of $\mathrm{E}^{\mathrm{i}}\{\mathrm{ox}, 298 \mathrm{~K}\}$ are in good agreement with values previously determined for $\mathrm{E}^{\prime}\left\{\right.$ ox, 298K\} with Eq. 3 (Fig. 5). As an example, $\mathrm{E}^{\mathrm{i}}\{$ ox, 298K\} $\approx 2.9$ $\pm 0.2 \mathrm{GPa}$ after 1010 hours, while $\mathrm{E}^{\prime}\{\mathrm{ox}, 298 \mathrm{~K}\} \approx 2.8 \pm 0.2 \mathrm{GPa}$. 
- In contrast, $\mathrm{E}^{\mathbf{1}}$ remains constant versus exposure time in the sample core. Its value has the same order of magnitude as the initial value of the storage modulus (determined by DMA): $\mathrm{E}^{\mathrm{i}}\{$ core, $298 \mathrm{~K}\}=\mathrm{E}^{\prime}\{$ core, $298 \mathrm{~K}\} \approx 2.3 \pm 0.2 \mathrm{GPa}$.

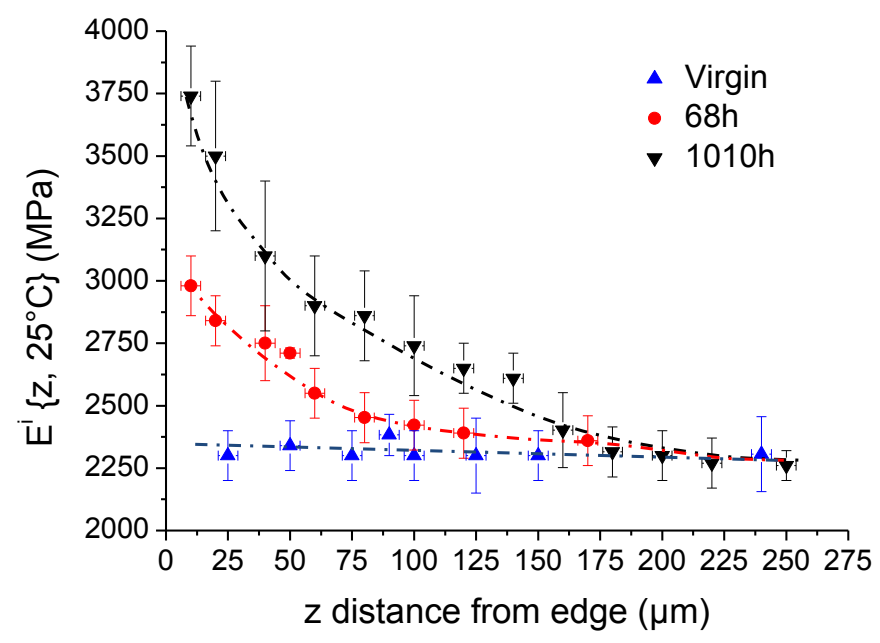

Figure 6: Indentation elastic modulus $\left(E^{i}\right)$ versus distance from sample edge $(\mathrm{z})$ after $0 \mathrm{~h}, 68 \mathrm{~h}$ and $1010 \mathrm{~h}$ at $200^{\circ} \mathrm{C}$ in air. Average values have been determined from 20 nano-indentation measurements.

\section{Discussion}

\subsection{Glass transition temperature}

Except in scarce cases where the composite matrix contains double bond (for instance in epoxies crosslinked by methyltetrahydrophthalic anhydride (MHTA) [19]), oxidation induces essentially chain scissions and these latter induce a decrease in the glass transition temperature $\mathrm{T}_{\mathrm{g}}$.

Chain scissions result from radical rearrangement (in particular $\beta$ scission of $\mathrm{PO}^{\circ}$ radicals) and thus, can occur only in initiation or termination. However, since the kinetic regime is always close to steady-state, initiation and termination rates are almost equal and it is thus licit to consider that chain scissions occur only in initiation:

$\frac{d S}{d t}=\frac{1}{\rho_{0}} \gamma_{1} k_{1}[\mathrm{POOH}]^{\delta}$

where $S$ is the number of moles of chain scission per mass unit and $\rho_{0}$ is the initial polymer density.

In contrast, crosslinking results from bimolecular termination of radicals:

$\frac{d X}{d t}=\frac{1}{\rho_{0}}\left\{\gamma_{4} k_{4}\left[P^{\circ}\right]^{2}+\gamma_{5} k_{5}\left[P^{\circ}\right]\left[P O_{2}^{\circ}\right]+\gamma_{6} k_{6}\left[P O_{2}^{\circ}\right]^{2}\right\}$

where $\mathrm{X}$ is the number of moles of crosslinking events per mass unit. 
Chain scission and crosslinking modify the structure of the macromolecular network. In ideal networks with trifunctional crosslinks (such as diamine crosslinked epoxies), each chain scission eliminates three elastically active chains (EACs) and two nodes. In contrast, each crosslinking event creates two EACs and one node (Fig. 7). In a first approach, the changes of nodes functionality are not taken into account. Moreover-Indeed knowing that in our process chain scission process is predominant, functionality changes induced by the crosslinking process ean-could be neglected.
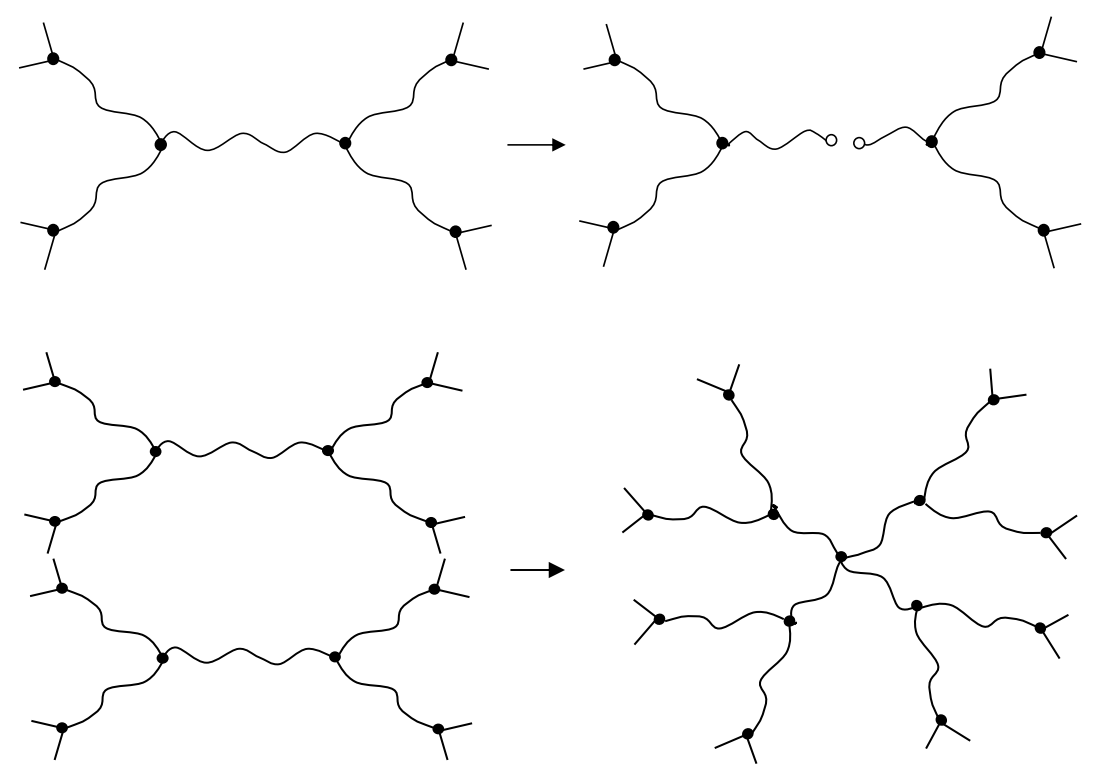

Figure 7: Schematization of a random chain scission (above) and a crosslinking event (below) in a network with initial trifunctional nodes.

Thus, the general relationships between the concentration of EACs $(v)$ and nodes $(n)$ and the number of chain scissions (S) and crosslinking events $(\mathrm{X})$ can be written:

$v=v_{0}-3 S+2 X \quad$ and $\quad n=n_{0}-2 S+X$

where $v_{0}, n_{0}, v$ and $n$ are the concentrations of EACs and nodes before and after ageing respectively.

$T_{g}$ is an increasing function of $n$. There are many relationships between $T_{g}$ and $n$ in the literature, but the better one is, to our opinion [20], the Di Marzio's equation [10]:

$T_{g}=\frac{T_{g l}}{1-K_{D M} F n}$

where $\mathrm{K}_{\mathrm{DM}}$ is an universal constant $\left(\mathrm{K}_{\mathrm{DM}} \approx 3\right), \mathrm{F}$ the flex parameter (characterizing the flexibility of EAC) and $\mathrm{T}_{\mathrm{gl}}$ the glass transition temperature of an hypothetical linear polymer containing all the structural units of the epoxyde network under study except crosslinks. 
In ideal networks, the concentration of nodes is linked to the concentration of EACs by:

$n=\frac{2}{f} v$

where $\mathrm{f}$ is the node functionality, i.e. the number of EACs connected to a node.

In this case, Eq. 8 can be rewritten:

$T_{g}=\frac{T_{g l}}{1-\frac{2}{f} K_{D M} F v}$

i.e. for diamine crosslinked epoxies (with $f=3$ ):

$T_{g}=\frac{T_{g l}}{1-\frac{2}{3} K_{D M} F v}$

Both parameters $\left(\mathrm{T}_{\mathrm{gl}}\right.$ and $\left.\mathrm{F}\right)$ can be determined by considering the structure of the virgin network. In the Tactix network under study, two constitutive repetitive units (CRU 1 and CRU 2) coexist in equimolar proportions (Fig. 8). 
<smiles></smiles>

CRU 1

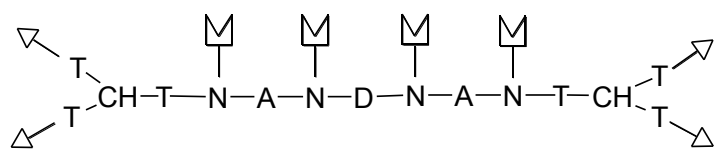

CRU 2

With

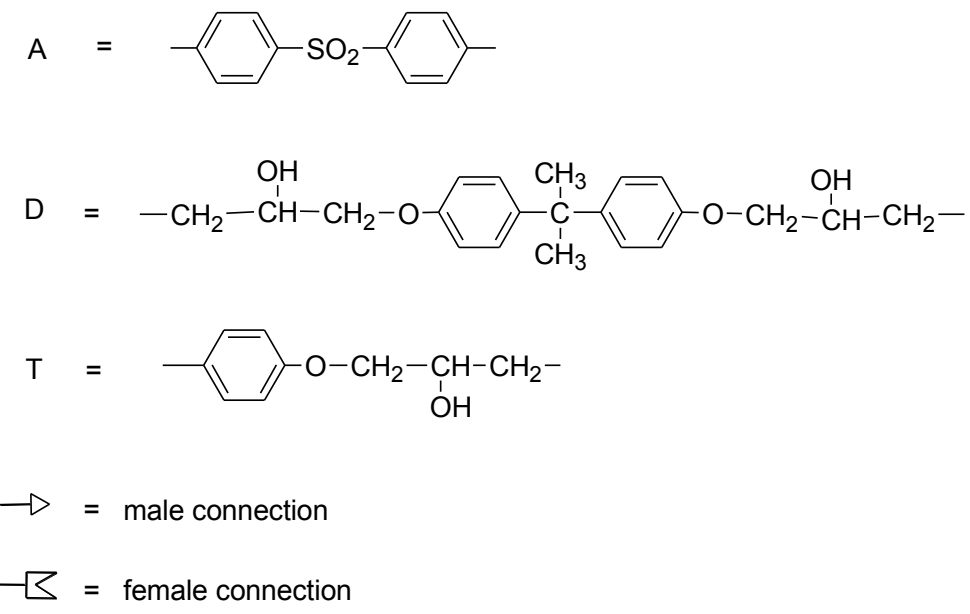

Figure 8: Constitutive repetitive units of the ideal Tactix network under study.

Each CRU contains three types of EACs (noted A, D and T) and four types of trifunctional nodes (noted ADT, ATT, ADD and TTT). Their main characteristics are given in Tab. 2.

Table 2: Number of EACs (N) and nodes (n) in CRU 1 and CRU 2, and the resulting average unit $\left(\mathbf{C R U}_{\text {moy }}\right)$.

\begin{tabular}{|c|c|c|c|c|}
\cline { 3 - 5 } \multicolumn{1}{c|}{} & CRU 1 & CRU 2 & CRU $_{\text {moy }}$ \\
\hline \multirow{4}{*}{$\mathbf{N}$} & A & 2 & 2 & 2 \\
& D & 1 & 1 & 1 \\
& T & 6 & 6 & 6 \\
& All & 9 & 9 & 9 \\
\hline \multirow{4}{*}{$\mathbf{n}$} & ADT & 1.5 & 2 & 1.75 \\
& ATT & 2.25 & 2 & 2.125 \\
& ADD & 0.25 & 0 & 0.125 \\
& TTT & 2 & 2 & 2 \\
& All & 6 & 6 & 6 \\
\hline
\end{tabular}


The main characteristics of the resulting average unit $\left(\mathrm{CRU}_{\text {moy }}\right)$ composed of equimolar proportions of CRU 1 and CRU 2 are also reported in Table 2. Its molecular weight is:

$\mathrm{M}_{\mathrm{UCR}}=1674.2 \mathrm{~g} \cdot \mathrm{mol}^{-1}$

Thus, its concentrations of EACs and nodes are:

$n_{0}=\frac{\sum n_{i}}{M_{U C R}}=\frac{6}{1.67}=3.6 \mathrm{~mol} \cdot \mathrm{kg}^{-1}$

$v_{0}=\frac{3}{2} n_{0}=\frac{\sum N_{i}}{M_{U C R}}=\frac{9}{1.67}=5.4 \mathrm{~mol} \cdot \mathrm{kg}^{-1}$

$\mathrm{T}_{\mathrm{gl}}$ was obtained from a simple "copolymer" law:

$M_{U C R} T_{g l}^{-1}=\sum M_{i} T_{g i}^{-1}$

where $\mathrm{M}_{\mathrm{i}}$ is the molecular weight of atom group $\mathrm{i}$ (in $\mathrm{CRU}_{\text {moy }}$ ) and $\mathrm{T}_{\mathrm{gi}}$ is its elementary contribution to glass transition temperature.

Values of $\mathrm{M}_{\mathrm{i}}$ and $\mathrm{T}_{\mathrm{gi}}$ used for the determination of $\mathrm{T}_{\mathrm{gl}}$ are reported in Tab. 3 [21]. It was found that:

$\mathrm{T}_{\mathrm{gl}}=353.7 \mathrm{~K}$ for ideal Tactix network under study.

Table 3: Molecular weight $\left(\mathrm{M}_{\mathrm{i}}\right)$ and elementary contribution to glass transition temperature $\left(\mathrm{T}_{\mathrm{gi}}\right)$ of atom groups composing the EACs of $\mathrm{CRU}_{\text {moy }}[21]$.

\begin{tabular}{|c|c|c|c|}
\hline & $\begin{array}{c}\mathbf{M}_{\mathbf{i}} \\
\left(\mathrm{g} \cdot \mathbf{m o l}^{-1}\right)\end{array}$ & $\mathbf{T}_{\mathrm{gi}}(\mathbf{K})$ & $\begin{array}{c}\mathrm{M}_{\mathrm{i}} \mathbf{T}_{\mathrm{gi}}{ }^{-1} \\
\left(\mathrm{~g} \cdot \mathrm{mol}^{-1} \cdot \mathrm{K}^{-1}\right)\end{array}$ \\
\hline$-\mathrm{SO}_{2}-$ & 64.1 & 624.0 & $10.2710^{-2}$ \\
\hline & 76.1 & $\begin{array}{l}459.9^{*} \\
387.6^{* *}\end{array}$ & $\begin{array}{c}16.5510^{-2} * \\
19.6310^{-2} * *\end{array}$ \\
\hline$-\mathrm{O}-$ & 16.0 & 250.0 & $6.4010^{-2}$ \\
\hline$-\mathrm{CH}_{2}-$ & 14.0 & 192.3 & $7.2610^{-2}$ \\
\hline $\begin{array}{c}-\mathrm{CH}- \\
\stackrel{\mathrm{O}}{\mathrm{H}} \mathrm{H}\end{array}$ & 30.0 & 433.3 & $6.9210^{-2}$ \\
\hline$\stackrel{\mathrm{I}}{\mathrm{C}} \mathrm{H}_{3}$ & 42.1 & 617.6 & $6.8210^{-2}$ \\
\hline
\end{tabular}

* if one side conjugated with neighboring group (e.g. with $\left.\mathrm{SO}_{2}\right)$; ** if non-conjugated. 
In contrast, $\mathrm{F}$ was calculated from a series of empirical equations:

$F=\frac{\sum n_{i} \cdot F_{i}}{\sum_{i} n_{i}}$

where $n_{i}$ is the number of nodes of type $i$ (in $C R U_{\text {moy }}$ ), and $F_{i}$ is their elementary contribution to flex parameter:

$F_{i}=\frac{\sum N_{k} \cdot m_{k}}{\sum N_{k}}$

where $\mathrm{N}_{\mathrm{k}}$ is the number of EACs of type $\mathrm{k}$ connected to nodes of type $\mathrm{i}$ and $\mathrm{m}_{\mathrm{k}}$ is the average molecular weight of the elementary segment containing only one chemical bond able to rotation:

$m_{k}=\frac{M_{k}}{\gamma_{k}}$

where $\mathrm{M}_{\mathrm{k}}$ is the molecular weight of EACs of type $\mathrm{k}$ and $\gamma_{\mathrm{k}}$ is their number of chemical bonds able to rotation, i.e. all chemical bonds except double bonds.

Values of $\mathrm{M}_{\mathrm{k}}, \gamma_{\mathrm{k}}$ and $\mathrm{m}_{\mathrm{k}}$ used for the determination of $\mathrm{F}_{\mathrm{i}}$, then $\mathrm{F}$, are reported in Tab. 4. It was found that:

$\mathrm{F}=31.8 \mathrm{~g} \cdot \mathrm{mol}^{-1}$ for ideal Tactix network under study.

Table 4: Molecular weight $\left(M_{k}\right)$, number of chemical bonds able to rotation $\left(\gamma_{k}\right)$ and average molecular weight of elementary segment $\left(m_{k}\right)$ of the EACs composing $C R U_{\text {moy. }}$.

\begin{tabular}{|c|c|c|c|}
\hline & $\mathrm{M}_{\mathrm{k}}\left(\mathrm{g} \cdot \mathrm{mol}^{-1}\right)$ & $\gamma_{k}$ & $\mathrm{~m}_{\mathrm{k}}\left(\mathrm{g} \cdot \mathrm{mol}^{-1}\right)$ \\
\hline $\mathbf{A}$ & 216.1 & 4 & 54 \\
\hline D & 342 & 12 & 28.5 \\
\hline $\mathbf{T}$ & 150 & 6 & 25 \\
\hline
\end{tabular}

The numerical application of Eq. 11 leads to a value of:

$\mathrm{T}_{\mathrm{g}}=538.7 \mathrm{~K}$ for ideal TACTIX network, i.e. $265.7^{\circ} \mathrm{C}$.

This value is in satisfying agreement with experimental one determined by DMA:

$\mathrm{T}_{\alpha} \approx 536 \mathrm{~K}$, i.e. $263^{\circ} \mathrm{C}$.

Since Eq. 11 gives good predictive values of $T_{g}$, it was used to predict the changes in $T_{g}$ during thermal ageing. One can remark that derivation of Eq. 11 against $v$ gives:

$\frac{d T_{g}}{d v}=\frac{2}{3} K_{D M} F \frac{T_{g l}}{\left(1-\frac{2}{3} K_{D M} F v\right)^{2}}$

i.e. $\frac{d T_{g}}{d v}=\frac{2}{3} K_{D M} F \frac{T_{g}^{2}}{T_{g l}}$ 
i.e. $\frac{d T_{g}}{T_{g}^{2}}=-\frac{2 K_{D M} F}{3 T_{g l}} d v$

The integration of Eq. 18 leads finally to:

$\frac{1}{T_{g}}-\frac{1}{T_{g 0}}=-\frac{2 K_{D M} F}{3 T_{g l}}\left(v-v_{0}\right)$

i.e. $\frac{1}{T_{g}}-\frac{1}{T_{g 0}}=\frac{2 K_{D M} F}{3 T_{g l}}(3 S-2 X)$

where $T_{g 0}$ and $T_{g}$ are the values of glass transition temperature before and after ageing respectively.

Thus, as expected, chain scissions decrease $\mathrm{T}_{\mathrm{g}}$, whereas crosslinking increases $\mathrm{T}_{\mathrm{g}}$. Moreover, the magnitude of these changes is an increasing function of the initial $\mathrm{T}_{\mathrm{g}}$ value.

Example of $\mathrm{T}_{\mathrm{g}}$ changes in air at $200^{\circ} \mathrm{C}$ for Tactix network have been reported in Fig. 9 (left). It can be concluded that, in such ageing conditions, chain scissions are largely predominant over crosslinking.

Eq. 20 has been used to calculate the number of chain scissions versus ageing time, by neglecting crosslinking. This result is presented in Fig. 9 (right).
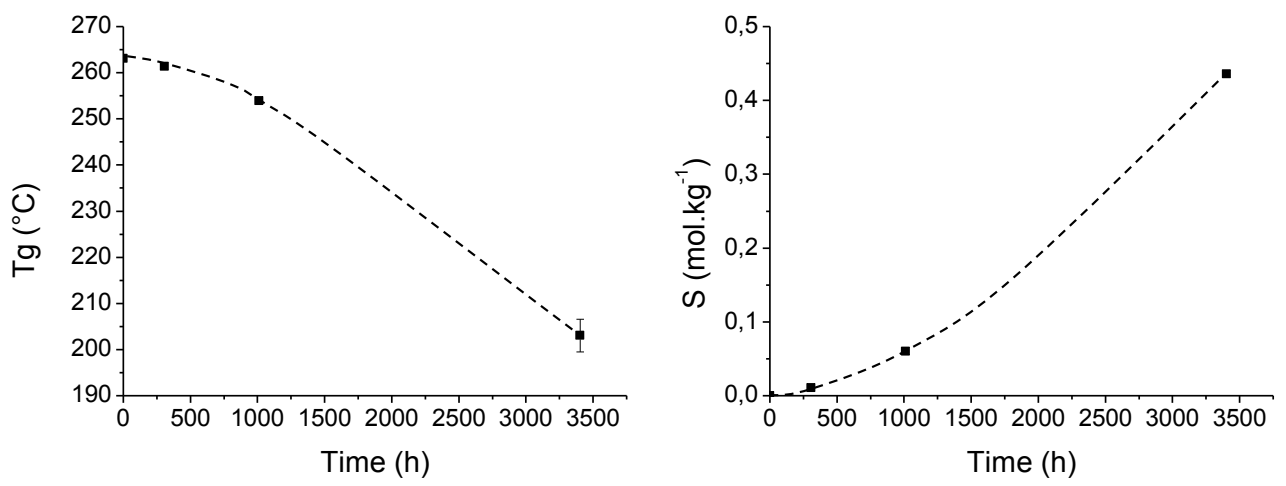

Figure 9: Glass transition temperature ( $T_{g}$, left) and number of chain scissions $(S$, right) versus ageing time at $200^{\circ} \mathrm{C}$ in air.

\subsection{Storage modulus}

Elastic modulus in glassy state depends essentially on two factors: cohesive energy density and local mobility (responsible for subglass transitions at temperatures lower than the temperature at which the elastic properties are measured). As an example, in the case of storage modulus it can be written [11]:

$E^{\prime}=E^{\prime}\left\{-273.15^{\circ} C\right\}\left(1-\alpha \frac{T}{T_{g}}\right)-\sum \Delta E_{n}^{\prime}$ 
where $E^{\prime}\{0 \mathrm{~K}\}$ is the Young's modulus at $0 \mathrm{~K}, \alpha$ is a coefficient of the order of 0.5 and $\Sigma \Delta \mathrm{E}_{\mathrm{n}}$ is the sum of modulus jumps corresponding to transitions of temperatures lower than $\mathrm{T}$.

Here, considering that there is no other significant subglass transition than $\beta$ and $\omega$, Eq. 21 simplifies:

$E^{\prime}=E^{\prime}\left\{-273.15^{\circ} \mathrm{C}\right\}\left(1-\alpha \frac{T}{T_{g}}\right)-\Delta E^{\prime}{ }_{\beta}-\Delta E^{\prime}{ }_{\omega} \quad$ with $0 \mathrm{~K}<\mathrm{T}<\mathrm{T}_{\mathrm{g}} \quad$ (Eq. 22)

In Fig. 10, the upper and lower dashed straight-lines delimiting each subglass transition correspond to the unrelaxed and relaxed Young's moduli respectively. The gaps between both straight-lines at $\beta$ and $\omega$ transitions correspond to the modulus jumps $\Delta \mathrm{E}_{\beta}$ and $\Delta \mathrm{E}_{\omega}$ respectively. It can be checked that Eq. 22 works well at $25^{\circ} \mathrm{C}$ taking:

$\mathrm{E}^{\prime}\{0 \mathrm{~K}\}=6400 \mathrm{MPa}, \alpha=0.59, \Delta \mathrm{E}_{\beta}=1800 \mathrm{MPa}$ and $\Delta \mathrm{E}_{\omega}=200 \mathrm{MPa}$ for the virgin Tactix network under study.

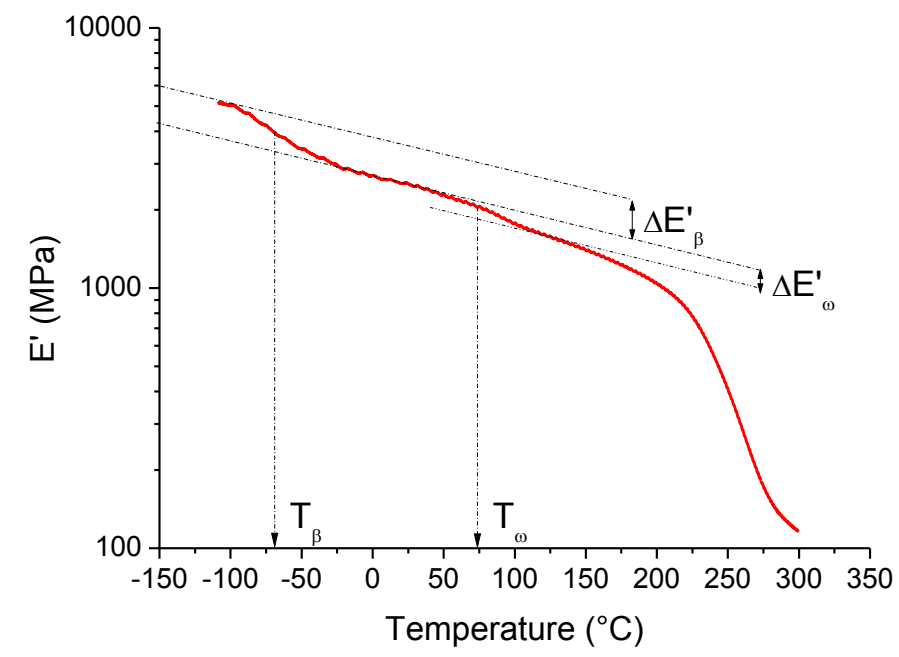

Figure 10: Storage modulus ( $E^{\prime}$ at $1 \mathrm{~Hz}, 2^{\circ} \mathrm{C} \cdot \mathrm{min}^{-1}$ ) versus temperature for the virgin Tactix network.

E' $\{0 \mathrm{~K}\}$ depends only on cohesive energy density $\mathrm{e}_{\mathrm{C}}$ [22]. It can be written:

$\mathrm{E}^{\prime}\{0 \mathrm{~K}\}=$ b.e $\mathrm{e}$

where $b \approx 11-12$ for a wide series of diamine crosslinked epoxies [20].

$\mathrm{e}_{\mathrm{C}}$ can be determined by using the empirical method proposed by Small [23]:

$e_{c}=\left(\frac{C}{V}\right)^{2}$

where $\mathrm{C}$ and $\mathrm{V}$ are the molar attraction constant and molar volume of the virgin network respectively.

According to Small, C and V obey an additive law: 
$\mathrm{C}=\Sigma \mathrm{C}_{\mathrm{i}} \quad$ and $\quad \mathrm{V}=\Sigma \mathrm{V}_{\mathrm{i}}$

(Eq. 25)

where $\mathrm{C}_{\mathrm{i}}$ and $\mathrm{V}_{\mathrm{i}}$ are the contributions of atom group $\mathrm{i}$ (in $\mathrm{CRU}_{\text {moy }}$ ) to $\mathrm{C}$ and $\mathrm{V}$ respectively.

Values of $C_{i}$ and $V_{i}$ used for the determination of $C$ and $V$, then $e_{C}$, are given in Tab. 5 .

Table 5: Elementary contribution to molar attraction constant $(C)$ and molar volume $(V)$ of the atom groups composing CRUmoy. According to Van Krevelen [24] and Fedors [25].

\begin{tabular}{|c|c|c|}
\hline & $\begin{array}{c}\mathrm{C}_{\mathrm{i}} \\
\left(\mathrm{J}^{1 / 2} \cdot \mathrm{cm}^{3 / 2} \cdot \mathrm{mol}^{-1}\right)\end{array}$ & $\begin{array}{c}\mathbf{V}_{\mathbf{i}} \\
\left(\mathrm{cm}^{3} \cdot \mathbf{m o l}^{-1}\right)\end{array}$ \\
\hline$-\mathrm{SO}_{2}-$ & 845 & 19.6 \\
\hline & 1660 & 89.4 \\
\hline$-\mathrm{O}-$ & 200 & 3.8 \\
\hline$-\mathrm{CH}_{2}-$ & 275 & 16.1 \\
\hline $\begin{array}{c}-\mathrm{CH}- \\
\stackrel{\mathrm{O}}{\mathrm{H}} \mathrm{H}\end{array}$ & 725 & 9.0 \\
\hline $\begin{array}{r}\mathrm{CH}_{3} \\
-\stackrel{1}{\mathrm{C}}- \\
\stackrel{!}{\mathrm{C}} \mathrm{H}_{3}\end{array}$ & 755 & 47.8 \\
\hline$-\underset{l}{\mathrm{CH}}-$ & 115 & -1.0 \\
\hline $\mathrm{N}-$ & 125 & -9.0 \\
\hline
\end{tabular}

The numerical application of Eqs 23 and 24 leads to a value of:

$\mathrm{e}_{\mathrm{C}}=554.6 \mathrm{MPa}$

i.e. to a stability parameter of:

$\delta=\mathrm{e}_{\mathrm{C}}^{1 / 2}=23.5 \mathrm{MPa}^{1 / 2}$

These are the values expected for an epoxide network with a moderate concentration of polar groups [26]. As an indication, for the ideal Tactix network under study, hydroxyl concentration is:

$[O H]=\frac{8}{M_{U C R}}=4.8 \mathrm{~mol} \cdot \mathrm{kg}^{-1}$ 
Finally, the numerical application of Eq 23 leads to a value of:

$\mathrm{E}^{\prime}\{0 \mathrm{~K}\} \approx 6380 \pm 280 \mathrm{MPa}$ for the ideal Tactix network under study.

This value is in satisfying agreement with $E^{\prime}\{0 \mathrm{~K}\}$ value extrapolated in Figure 10.

At low conversion ratio of oxidation process, $\mathrm{e}_{\mathrm{C}}$ remains almost constant (it increases very slightly since it depends on polarity). As a result, E’ $\{0 \mathrm{~K}\}$ remains almost constant.

In contrast, as shown in Fig. 3, chain scissions affect significantly all other viscoelastic properties. Indeed, they decrease the glass transition temperature, and they increase the storage modulus at glassy plateau between $T_{\beta}$ and $T_{\alpha}$. This phenomenon is called "internal antiplasticization". It results from the disappearance of the $\beta$ motions having the highest degree of cooperativity, i.e. responsible for the high temperature side of the $\beta$ dissipation band. Storage modulus at $25^{\circ} \mathrm{C}$ and area of $\beta$ dissipation band have been determined for unoxidized and oxidized Tactix networks. Reduction in $\beta$ activity has been calculated as:

$\Delta \beta=\frac{A_{\beta 0}-A_{\beta}}{A_{\beta 0}}$

where $A_{\beta 0}$ and $A_{\beta}$ are areas of $\beta$ dissipation band before and after ageing respectively.

Then, storage modulus at $25^{\circ} \mathrm{C}$ has been plotted versus reduction in $\beta$ activity in Fig. 12. It can be observed that there is clearly a linear relationship between both quantities:

$E^{\prime}\{$ ox, $298 K\}=E^{\prime}\{$ core, $298 K\}+\mu . \Delta \beta$

with $\mu=1870 \mathrm{MPa}$.

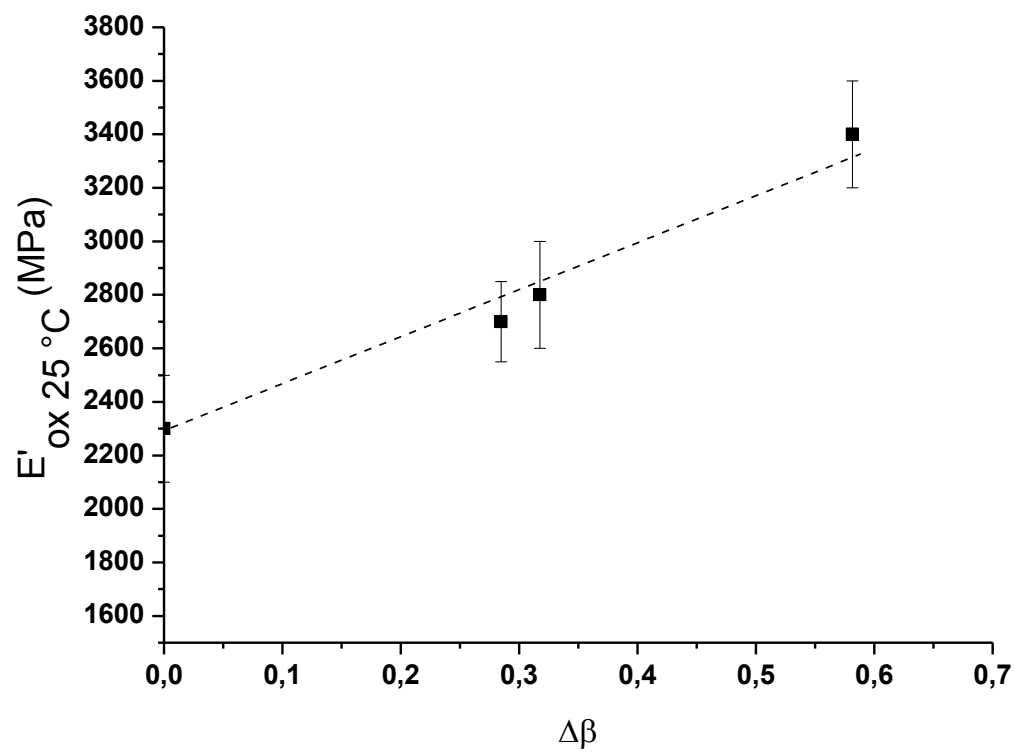


Figure 12: Average storage modulus of oxidized layer $E^{\prime}\{0 x, 298 K\}$ versus reduction in $\beta$ activity $(\Delta \beta)$ at $200^{\circ} \mathrm{C}$ in air.

Knowing that $\beta$ transition motions are due to $-\mathrm{O}-\mathrm{CH}_{2-}$ groups, it will be tried to find a relationship between $\left[\mathrm{O}-\mathrm{CH}_{2}\right]$ and $\beta$ transition activity.

\section{Conclusion}

Thermal oxidation of ideal Tactix network at $200^{\circ} \mathrm{C}$ in air consists in an "internal antiplasticization". Indeed, the predominant chain scission process leads to a catastrophic decrease in the glass transition temperature, but also, at the same time, to a significant increase in the storage modulus at the glassy plateau between $\mathrm{T}_{\beta}$ and $\mathrm{T}_{\alpha}$.

Di Marzio and Gilbert's theories have been used to establish relationships between the glass transition temperature and number of chain scissions, and between the storage modulus and $\beta$ activity respectively. The challenge is now to establish a last relationship between the $\beta$ activity and the concentration of chemical groups responsible for the $\beta$ dissipation band. This work is in progress.

In a near future, both relationships will be interfaced with the chemical unit of the nonempirical kinetic model, previously developed in our laboratory, with the intention of predicting the consequences of the thermal oxidation of neat epoxy matrices on their viscoelastic properties.

\section{Acknowledgement}

This work has been performed in the framework of the COMPTINN project whose the aim is to select composite materials for warm to hot structural applications (typically between 150 and $400^{\circ} \mathrm{C}$ ) in civil aircraft industry. The authors gratefully acknowledged the financial support of OSEO-DGCIS within the ASTech and Aerospace Valley competitive clusters.

\section{References}

[1] X. Colin, C. Marais, J. Verdu, A new method for predicting the thermal oxidation of thermoset matrices: application to an amine crosslinked epoxy. Polym. Testing 20(7), pp. 795-803, 2001.

[2] X. Colin, C. Marais, J. Verdu, Kinetic modelling and simulation of gravimetric curves: application to the oxidation of bismaleimide and epoxy resins. Polym. Degrad. Stab. 78(3), pp. 545-553, 2002.

[3] J. Decelle, N. Huet, V. Bellenger, Oxidation induced shrinkage for thermally aged epoxy networks. Polym. Degrad. Stab. 81(2), pp. 239-248, 2003. 
[4] X. Colin, C. Marais, J. Verdu, Kinetic modelling of the stabilizing effect of carbon fibres on thermal ageing of thermoset matrix composites. Compos. Sci. Technol. 65, pp. 117-127, 2005.

[5] L. Achimsky, L. Audouin, J. Verdu, J. Rychly, L. Matisova-Rychla, On a transition at $80{ }^{\circ} \mathrm{C}$ in polypropylene oxidation kinetics. Polym. Degrad. Stab. 58(3), pp. 283-289, 1997.

[6] L. Olivier, N.Q. Ho, J.C. Grandidier, M.C. Lafarie-Frenot, Characterization by ultramicro indentation of an oxidized epoxy polymer: Correlation with the predictions of a kinetic model of oxidation. Polym. Degrad. Stab. 93, pp. 489-497, 2008.

[7] M. Gigliotti, L. Olivier, D.Q. Vu, J.C. Grandidier, Local shrinkage and stress induced by thermo-oxidation in composite materials at high temperatures. J. Mech. Phys. Solids 59, pp. 696-712, 2011.

[8] D.Q. Vu, M. Gigliotti, M.C. Lafarie-Frenot, Experimental characterization of thermooxidation-induced shrinkage and damage in polymer-matrix composites. Compos. A43, pp. 577-586, 2012.

[9] N. Rasoldier, X. Colin, J. Verdu, M. Bocquet, L. Olivier, L. Chocinski-Arnault, M.C. Lafarie-Frenot, Model systems for thermo-oxidized epoxy composite matrices. Compos. A39, pp. 1522-1529, 2008.

[10] E. A. Di Marzio, On the second-order transition of a rubber. J. Res. (NBS) A68, pp. 611-617, 1964.

[11] D.G. Gilbert, Ashby M.F., Beaumont P.W.R., Modulus maps for amorphous polymers. J. Mater. Sci. 21, pp. 3194-3210, 1986.

[12] User Guide 423 Revision A, Nanoindentation for Nanoscope Software Version 7 , Veeco Metrology Group, 2007.

[13] L. Heux, J.L. Halary, F. Lauprêtre, L. Monnerie, Dynamical mechanical and ${ }^{13} \mathrm{C}$ n.m.r. investigations of molecular motions involved in the $\beta$ relaxation of epoxy networks based on DGEBA and aliphatic amines. Polymer 38 (8), pp. 1767-1778, 1997.

[14] GA Pogany. Gamma relaxation in epoxy resins and related polymers. Polymer 11, pp. 66-78, 1970.

[15] D. Colombini, J. Martinez-Vega, G. Merle, Influence of hydrothermal ageing and thermal treatments on the viscoelastic behaviour of DGEBA-MCDEA epoxy resin, Polym. Bull. 48, pp. 75-82, 2002.

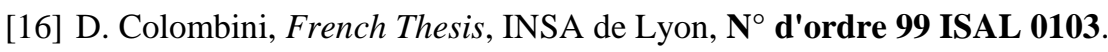

[17] V. Gupta, L. Drzal, C. Lee, M. Rich, Temperature dependence of some mechanical properties of a cured epoxy resin system, Polym. Eng. Sci. 25 (13), pp. 812-823, 1985.

[18] M. Schimbo, M. Ochi, M. Yoshizumi, Mechanical and dielectric relaxations of epoxyde resins containing the spiro-ring structure - II. Effects of the introduction of methoxy branches on low-temperature relaxations of epoxy resins, J. Polym. Sci.: Polym. Phys. 25, pp. 1817-1827, 1987.

[19] M. Le Huy, V. Bellenger, M. Paris, J. Verdu, Thermal oxidation of anhydride cured epoxies. Part I, II and III. Polym. Degrad. Stab. 35, pp. 77-86, 1992, 35, pp. 171-179 1992, and 41(2), pp. 149-156, 1993. 
[20] V. Bellenger, E. Morel, J. Verdu, Effect of structure on the glass transition temperature of amine crosslinked epoxies, J. Polym. Sci.: Polym. Phys. 25, pp. 12191234, 1987.

[21] D.W. Van Krevelen Properties of Polymers: Their correlation with chemical structure; their numerical estimation and prediction from additive group contributions. Fourth edition, Elsevier, Amsterdam, Chapter 6, pp. 132-145, 2009.

[22] A. Bondi, Physical properties of molecular liquids, crystal and glass. Wiley, NewYork, 1998.

[23] Small P.A., Some factors affecting the stability of polymers, Journal of Applied Chemistry, 9 (2), pp. 71-80, 1953.

[24] D.W. Van Krevelen Properties of Polymers: Their correlation with chemical structure; their numerical estimation and prediction from additive group contributions. Fourth edition, Elsevier, Amsterdam, Chapter 6, pp. 194-197, 2009.

[25] R.F. Fedors, Methods for estimating both the solubility parameter and molar volumes of liquids. Polymer Engineering Science, 14 (2), pp. 147-154, 1974.

[26] J.-P. Pascault, H. Sautereau, J. Verdu, R.J.J. Williams, Thermosetting Polymers. Marcel Dekker, New-York, Chapter 10, pp. 282-322, 2002. 